ORIGINAL ARTICLE

\title{
Awareness about Workplace Harassment among Female Nursing Students and Nursing Staff of a Teaching Hospital in Lahore
}

\author{
Tahseen Kazmi ${ }^{1}$, Jamal Abdul Nasir ${ }^{2}$, Umaila Qayyum ${ }^{3}$, Tehreem Tahir ${ }^{4}$ \\ Professor, Department of Community Medicine, Central Park Medical College, Lahore ${ }^{1}$ \\ Senior Demonstrator, Department of Community Medicine, Shalamar Medical \& Dental College, Lahore ${ }^{2}$ \\ $4^{\text {th }}$ year MBBS Student, Department of Community Medicine, Shalamar Medical \& Dental College, Lahore ${ }^{3}$ \\ $4^{\text {th }}$ year MBBS Student, Department of Community Medicine, Shalamar Medical \& Dental College, Lahore ${ }^{4}$
}

doi: https://doi.org/10.53685/jshmdc.v2i2.6

\begin{abstract}
Background: Harassment of working women is a common social and human rights problem and healthcare settings are no exception. This unacceptable situation has many avoidable determinants that need preventive measures to ensure, safe and secure working environment for nurses.

Objectives: To assess the knowledge and understanding among female nursing students and nursing staff about workplace harassment in a tertiary healthcare facility.

Methods: It was a cross-sectional study conducted at Tertiary care hospital Lahore from July to September 2018. Convenient sampling technique was used to collect data. Verbal informed consent of voluntary participants was taken. Anonymity and confidentiality was assured. SPSS version 21 was used for data analysis. The participants $(\mathrm{n}=80)$ comprised of senior female nurses students $(62.5 \%)$ and senior nursing staff (37.5\%), aged 18 to 46 years.

Results: Awareness about common harassment forms was adequate (81.3\%). Adverse effects included mental health problems $(83.8 \%)$ and low self-esteem $(72.5 \%)$. A large percentage of nurses $(62.5 \%)$ intended to report such personal incident to institutional head and $72.5 \%$ were willing to accompany victims for such reporting. $77.5 \%$ desired arranging informative sessions and holding counseling for victims $(78.8 \%)$ at workplace. Only $22.5 \%$ had vague idea about official protective legal frameworks.

Conclusions: Workplace harassment of female workers is quite prevalent but under-reported phenomena in Pakistan. All organizations and institutions must have a harassment policy to protect the females.
\end{abstract}

Key Words: Harassment, Females nurses, Hospital

How to cite this article: Kazmi T, Nasir JA, Qayyum U, Tahir T. Awareness about workplace harassment among female nursing students and nursing staff of a teaching hospital in lahore. JSHMDC. 2021; 2(2): 64-71. doi: 10.53685/jshmdc.v2i2.6

This article is published in JSHMDC under the terms of the Creative Commons Attribution License (http://creativecommons.org/licenses/by/4.0), which permits unrestricted use, distribution, and reproduction in any medium, provided the original work is properly cited.

\author{
Corresponding Author: \\ Prof. Dr Tahseen Kazmi \\ Community Medicine Department \\ Central Park Medical College, Lahore \\ Email address: tahseenkazmi@gmail.com \\ Received 30.04.2021, Revised 04.06.2021, \\ Accepted 05.10.2021
}




\section{INTRODUCTION}

The increasing participation of women in diverse practical fields has led them to work side by side with male colleagues. Harassment is defined as an improper and unwelcomed gesture that invariably fills the other person with a sense of indignation and humiliation. Sexual harassment, a major type has become a global issue.

Other forms of harassment include verbal, physical, psychological and sexual. ${ }^{1}$ In a workplace setting, women consider harassment to be an act that tends to dishonor, oppress and embarrass the other person creating an intimidating work environment, adversely affecting their mental and social health as well as their proficiency at work. It has been seen that most cases of sexual harassment do not end up being reported to the authorities. The reason behind is the fear of punishment or accusation of whistleblowing which might ruin a woman's career. Women have a firm belief that complaining about workplace abuse will not be taken seriously, and might end up into victim-shaming. They also fear that they might be told that harassment is a part of the process towards success. This leads to detrimental effects on their psychological and mental health as well as their careers and personal life. Along with that, it is also seen that the official proceedings to deal with complaints of harassment are more than merely a tokenistic effort and nothing substantial is done to deal with the problem. ${ }^{2}$

In a study conducted in 2016 at Lahore, reported $13.4 \%$ female house officers reported issues related to sexual harassment, $65.3 \%$ faced gender-based cultural constraints and $38.3 \%$ had gender based issues among female doctors. ${ }^{3}$ Our conservative societal mindset has yet not fully changed according to the emerging reality of women empowerment, the nursing profession still being marginalized in our healthcare system. Historically nursing professionals, under Florence Nightingale, formed a very hierarchical system where obedience was 'expected, encouraged, and for sure demanded'. The sexual harassment resulted in depression, anxiety and stress among $65.43 \%$ of nurses. ${ }^{4}$ The drivers of such offensive behavior in our healthcare system have to be identified to prevent such happenings at workplace.

For people working in human resources, the threats and incidents of work-related violence has a substantial number. This high exposure to recurring acts of violence causes a negative change in the staff's behavior towards the clients or patients. Bullying at workplace is not due to a small number of pathologically deranged individuals. Removing them from the institute cannot solve the problem. The solution lies beyond that. The organizations must play a central role. ${ }^{5}$

"The Protection against Harassment of Women at Workplace Act, 2010" (as amended in 2016) defined workplace harassment as, "any unwelcome sexual advance, request for sexual favors or other verbal or written communication or physical conduct of a sexual nature or sexually demeaning attitudes, causing interference with work performance or creating an intimidating, hostile or offensive work environment, or the attempt to punish the complainant for refusal to comply to such a request or is made a condition for employment" .6

"The Federal Ombudsperson for Protection against Harassment of Women at Workplace" has defined workplace harassment as; "Any unwelcome sexual advance, request for sexual favor or other verbal or written communication or physical conduct of a sexual nature or sexually demeaning attitudes, causing interference with work performance or creating an intimidating, hostile or offensive work environment, or the attempt to punish the complainant for refusal to comply to such a request or request is made a condition for employment". The same definition of harassment has been adopted by all the provincial ombudspersons for 
protection against harassment of women at workplace. Quite often, women are hesitant to make genuine complaints at their workplace due to many socio-cultural and religious constraints.

The rationale of the study was an attempt to create the basic awareness among local stakeholder regarding a sensitive and less talked issue involving safety of women at workplace in our traditional male dominated society. Further, the study was expected to enable the participants to identify their information gaps about all the available official forums and their legal privileges about their protection against harassment at the workplace. The objective of the present study was to assess the knowledge and understanding among the female nursing staff about workplace harassment in the tertiary hospital.

\section{MATERIALS AND METHODS}

A cross-sectional study was conducted from July 2018 to September 2018 at a tertiary care hospital of Lahore. Convenient sampling technique was used for collection of data. Permission of the institutional review board was obtained for conducting this small study. All the potential participants were assured about their individual anonymity and the confidentiality of their given input while seeking their informed verbal consent. The participants had also been given the additional choice to decline answering any of the asked questions. Total 80 female respondents voluntarily agreed to participate in the study. Among them 50 $(62.5 \%)$ were nursing students of third and final year of bachelor of nursing (BS) program, and the rest $(37.5 \%)$ were nursing staff. However, sample size was influenced by the usual cultural sensitivity and 'less talked' nature of the study topic. Ethical and safety recommendations for intervention research on violence against women by WHO (2016) were also considered for framing the study questions. Structured and pre-tested questionnaire was developed for data collection. Participants of the survey were asked questions about common modes of sexual harassment, frequency and type of harassment, protective measures taken by the victims and the impact of harassment on physical and mental health. Frequencies and percentages were calculated for data reporting.

\section{RESULTS}

Our study demonstrated that overall awareness among the respondents about common forms of harassment was significantly high (81.3\%). Participants described certain behaviors and acts of males as common forms of harassment; obscene gestures and uncomfortable sounds, sending inappropriate letters, text messages or voice mails, unnecessary staring, and passing uncalled remarks by male colleagues (Figure: 1). Majority of women remain shy and hesitant to report such incidents due to fear of being stigmatized by their colleagues. Women also faced lot of difficulties in lodging such complaints, and lack of formal institutional mechanisms to effectively handle such complaints at workplaces (Figure: 3). Respondents considered sexual harassment as the most common form of harassment at workplaces (Figure: 2). Regarding possible adverse effects of harassment on the victims, respondents referred to developing mental health problems, developing physical health problems, deciding to quit the job, avoiding employment wherever male colleagues work, low self-esteem, absenteeism, and decreased interest in one's job. More than half of all the respondents considered their own institution quite safe and secure for women.

Regarding improvement suggestions, $41.3 \%$ agreed to hold formal informative sessions about such matters at institution level. However, most of the females indicated willingness to help arrange and participate in the seminars planned on the matter in the institution. More than two third respondents liked educating women at their workplace about their own protection from 
harassment. Only one in five female nurses knew about 'the protection against harassment of women at workplace act, 2010 (as amended in 2016), and establishment of 'the offices of federal and provincial ombudspersons for protection against harassment of women at workplace'. Regarding remedial measures arranged for victims at workplace included encouraging them to gain confidence at workplace through counseling, holding inquiry of the incident without compromising victim's fame and essentially considering the available circumstantial evidence in inquiry (Figure: 3 ).

For disposal of proven offender, the respondents described that offender should be dismissed from employment for serious offence $(61.3 \%)$, giving the offender a warning in case of minor offence (56.3\%), culprit must formally apologize from victim for minor offence $(52.5 \%)$, and referral of the selected cases to office of the concerned federal or provincial ombudsperson for protection of women against harassment at workplace (58.8\%). However, no significant responses were received to three different open-ended parts of main questions which asked for participants' own relevant suggestions. There was decreased interest in job and deliberately skipping work in order to avoid contact with male harassers (Figure: 4).

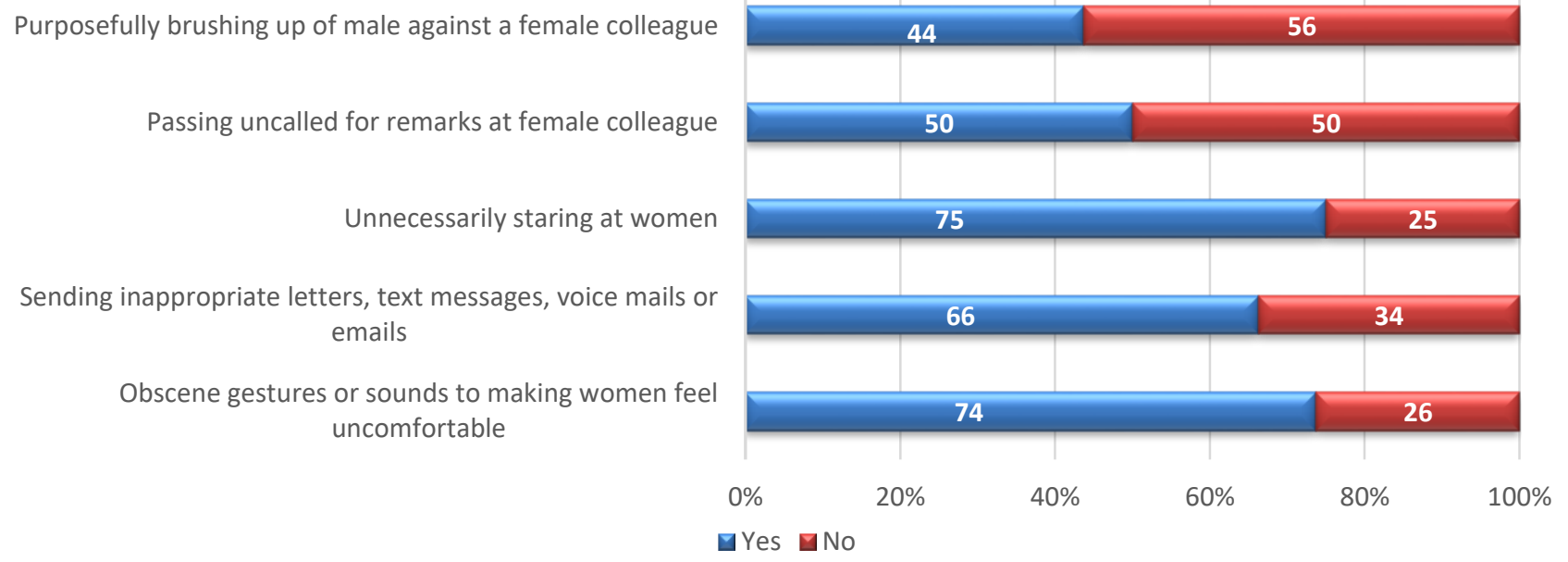

Figure 1: Common modes sexual harassment at workplace 


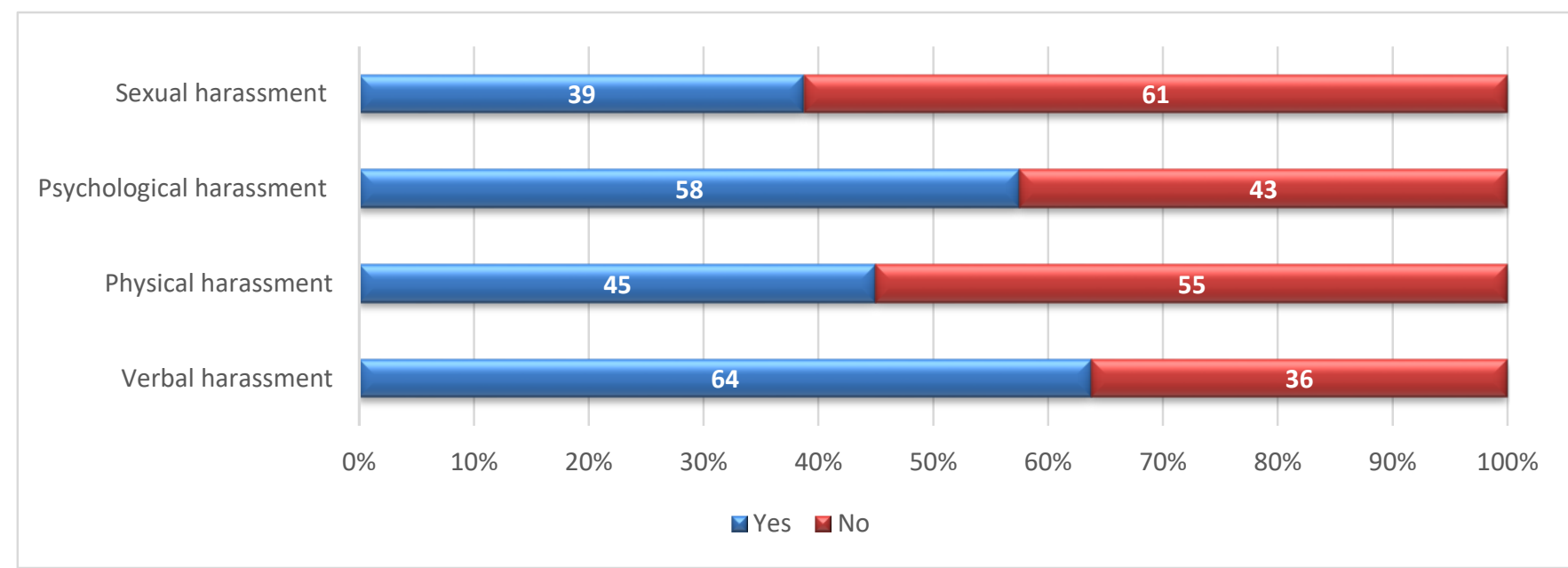

Figure 2: Frequency distribution of different types of harassment

Frequency of different type of harassment

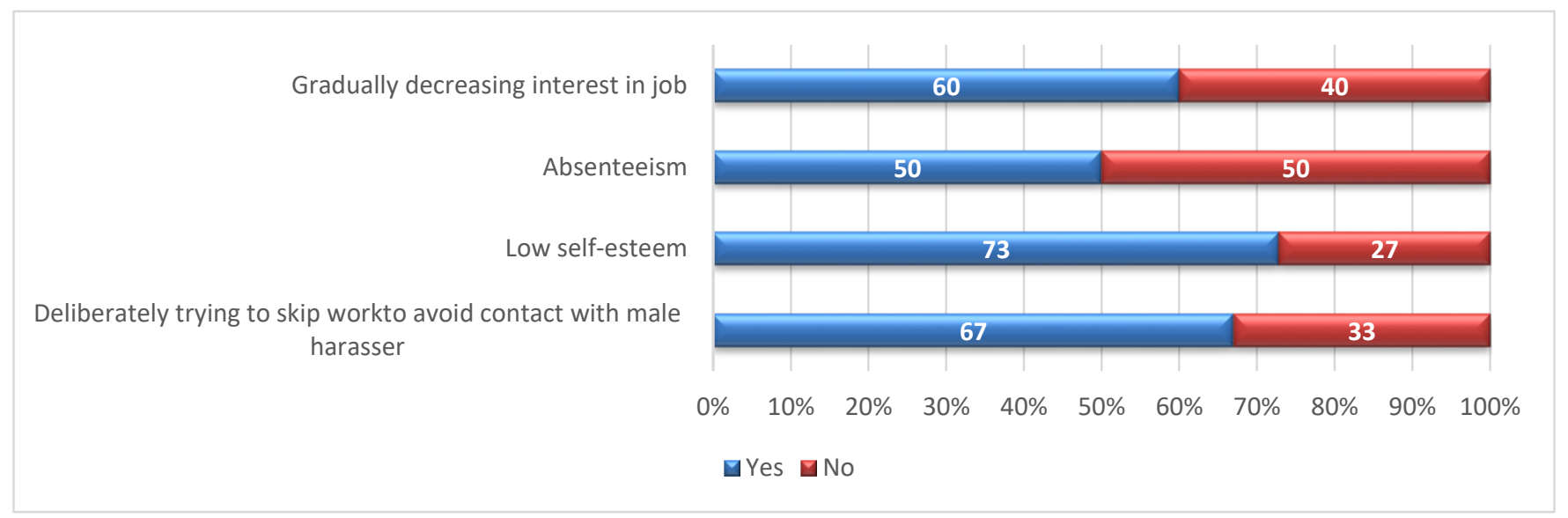

Figure 3: Specific protective measures against harassment of women

Holding of formal sessions about such like matters in your institution

Open display of the related information for inside the institution

Information about composition of institutional inquiry committee

Information about institutional complaint registration forum

Instructions about lodging complaints by victims or witness(es)

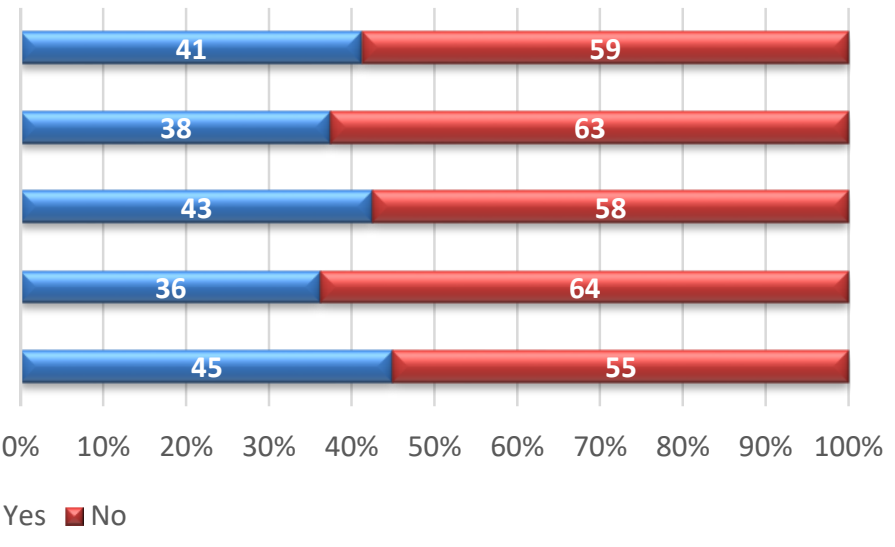

Figure 4: Impact of workplace harassment on job performance of effected female employee 


\section{DISCUSSION}

In our society, women have increasingly been participating in diverse practical fields including those traditionally labeled as 'male-specific'. They have assumed diverse hierarchical positions in public and private organizations on merit with a perceptible consciousness about their legal and human rights. However, the necessary gender sensitization of our conservative society is slow to catch up with this newly emerging and positive social reality.

A research conducted in 2015 showed that sexual harassment among nurses is prevalent up to $10 \%$. A survey done in Karachi showed equal incidences of harassment in government and private set-ups. The $47.8 \%$ of the perpetrators were patients' relatives and $32.6 \%$ were members of the staff. The victims ranged from 19 to 29 years of age. Nurses who had a work experience less than 5 years reported more incidents of harassment, along with that, nurses whose duty timings varied, suffered more from work-place harassment than those with fixed hours; it ranged from $80 \%$ to $85 \%$ in nurses who performed shift duties. $93.5 \%$ of nursing participants had considered the incident of sexual abuse as a typical case of workplace violence. ${ }^{8}$

A study undertaken in three main teaching hospitals of Peshawar about sexual harassment of staff and student nurses $(n=150)$ showed that $80 \%$ had sexual harassment experience, $66 \%$ cases occurred inside hospital. $65.3 \%$ of the respondents reported the incidences to management, but $70.7 \%$ were not satisfied from the measures taken. $50.7 \%$ had psychological effects, $40.7 \%$ had effects on their performance and $8 \%$ had health effects. They were mostly victimized by patients and their male visitors $(55.3 \%), 25.3 \%$ by doctors, $4.7 \%$ by their colleagues and $14.7 \%$ by administration. ${ }^{9}$ There is mounting evidence that abuse and mistreatment within the care team leads to worse outcomes for patients. ${ }^{10}$ A local study indicated that sexual harassment is significant predictor of low job satisfaction and low self-esteem among in-training nurses. ${ }^{11}$ Our study results also showed $73 \%$ nurses suffered from low self-steam due to harassment. A significant positive correlation has been found between general workplace harassment and posttraumatic stress symptoms. ${ }^{12}$ Among women, sexual harassment has been associated with a vast array of physical health problems e.g., elevated systolic blood pressure. ${ }^{13}$

The findings of a study conducted in 2017 among nurses (309) of two tertiary care public hospitals of Lahore showed that $73.1 \%$ of nurses reported experiencing some sort of violence in the last 12 months; with $53.4 \%$ suffering from physical violence, $57.3 \%$ from verbal violence, and $26.9 \%$ from sexual violence. The main perpetrators were reported to be male coworkers, patients, and attendants. ${ }^{14}$ These findings were similar to our study where nurses faced verbal harassment as the most common form with $64 \%$ nurses experiencing it during duty. Sexual harassment was also experienced by $39 \%$ of the nurses.

Present study findings showed that harassment of females working in all-gender healthcare centers lead to adverse effects on their job performance, health and social bearing. These findings were quite similar to workplace harassment study results in China in which high percentage of nurses suffered from stress, anxiety and other psychological problems after physical or sexual abuse. ${ }^{15-17}$ All the organizations and institutions of the country are legally bound to make policies and procedures for handling such grievances and preventing harassment experiences at workplaces. The amendment subsequently made in The Act, 2012 had further added 'educational institutions' and 'students' for implementation purpose as those were missed in earlier passed legislation. Nevertheless, the responsible and gendersensitized organizations maintain an effective remedial system through human resource 
management department, envisaging the official guidelines for prompt redress of grievances.

In our study, nurses mentioned verbal abuse as the most disturbing activity faced, and consequently they had mental trauma making them emotionally weak. A good percentage (72\%) of our respondents is willing to participate in awareness seminars at college and university levels. It is a legal obligation of the policy makers in institutions and organizations to prohibit gender discrimination and introduce practical measures that will raise general awareness among our nurses throughout the country.

Our findings reflect the dire need to increase the awareness among all the female students and the working women about the relevant protective legal framework available to them officially. Moreover, $45 \%$ participants had the knowledge to some extent about their own institutional instructions on the matter. The availability of purpose-specific online reporting system in organizations, addressed to a designated person, may ensure the arrangements that complainants can safely lodge complaints through giving a structured description along with circumstantial evidence.

Workplace policy should deal with both primary prevention i.e., how to prevent offensive behavior and secondary prevention i.e. how to help workers who have been offended and deal with the offender or offenders of harassment. In case of violence or threat of violence it will often be appropriate to turn the offender in to the police, since violence is against the law in all countries. This finding was also similar to various studies about punishment and reporting of serious cases of sexual harassment. ${ }^{18-21}$

\section{Limitations}

Limitation of this study included the small sample size, a tertiary care hospital having better security mechanism, traditionally sensitive and restricted nature of topic. Moreover, the questions were cautiously framed due to the possible restraining effect of the odd topic and the private healthcare setting. Hence, the veracity of input received from our respondents is likely to be influenced accordingly so possibly being less categorical in nature.

\section{CONCLUSION}

Workplace harassment of female workers is quite prevalent but under reported phenomena in Pakistan. All organizations and institutes must have a harassment policy to protect females. The harassment policy must be well known to the employees with an inbuilt system of reporting, follow-up and remedial measure for all incidences of physical, psychological and sexual harassment.

\section{Conflicts of interest}

All authors declared no conflicts of interest.

\section{Source of funding}

None

\section{Contributors}

TK: Conception, study design, drafted the manuscripts and final approval

JAN: Statistical analysis and reviewed it critically for important intellectual content

UQ: Data Collection, data Entry

TT: data collection and data entry

All authors approved the final version and signed the agreement to be accountable for all aspects of work.

\section{REFERENCES}

1. Australian Human Rights Commission: Sexual harassment in the workplace - The Legal Definition of Sexual Harassment. Available at https://humanrights.gov.au/our-work/sexual-harassmentworkplace-legal-definition-sexual-harassment. (Accessed on 15.4.2021)

2. Launer J. Sexual harassment of women in medicine: a problem for men to address. Postgrad Med J. 2018; 94(1108): 129-130. 
3. Akram MA, Rehman F, Rubab M, Aftab H, Sarwar MZ, Saeed Y, et al. Problem faced by female doctors regarding career development. PJMHS. 2016; 10(4): 1210-1213.

4. Mushtaq M, Sultana S, Imtiaz I. The trauma of sexual harassment and its mental health consequences among nurses. J Coll Physicians Surg Pak. 2015; 25(9): 675-679. 5. Jiao M, Ning N, Li Y, Cui Y, Sun H, Kang Z, et al. Workplace violence against nurses in Chinese hospitals: a cross-sectional survey. BMJ Open 2015; 5(3): e006719. https://doi.org/10.1136/bmjopen-2014-006719.

6 . The Protection against Harassment of Women at The Workplace Act, 2010" (as amended in 2016). Pakistan. Available at:

https://www.ilo.org/dyn/natlex/natlex4.detail?p_lang=en \&p_isn=86175. (Accessed on 10.03.2021)

7. The Federal Ombudsperson for Protection against Harassment of Women at Workplace. Pakistan. Available at http://www.fospah.gov.pk (Accessed on 10.05.2021)

8. Somani R, Karmaliani R, McFarlane J, Asad N, Hirani S. Sexual harassment towards nurses in Pakistan: are we safe. International Journal of Nursing Education. 2015; 8(2): 289-292.

9. Khan N, Begum S, Shaheen A. Sexual harassment against staff and student nurses in tertiary care hospitals Peshawar KP Pakistan. International journal of innovative research and development. 2015; 4(1): 285-292.

10. Mazer LM, Merrell SB, Hasty BN, Stave C, Lau JN. Assessment of programs aimed to decrease or prevent mistreatment of medical trainees. JAMA. 2018; 1(3): e180870.

11. Malik NI, Malik S, Qureshi N, Atta M. Sexual harassment as predictor of low self-esteem and job satisfaction among in-training nurses. FWU Journal of Social Sciences. 2014; 8(2): 107-116.

12. Malik S, Farooqi YN. General and sexual harassment as predictors of posttraumatic stress symptoms among female health professionals. World Journal of Medical ciences.2014; 10(1): 43-49.

13. World Health OrganizationBui .lding healthy and equitable workplaces for women and men : a resource for employers and worker representatives. World Health

Organization. 2011.

https://apps.who.int/iris/handle/10665/77350. (Accessed on 10.07.2021)

14. Jafree SR. Workplace violence against women nurses working in two public sector hospitals of Lahore, Pakistan. Nursing outlook. 2017; 65(4): 420-427.
15. Gong Y, Han T, Yin X, Yang G, Zhuang R, Chen Y, et al. Prevalence of depressive symptoms and work-related risk factors among nurses in public hospitals in southern China: a cross-sectional study. Sci Rep 2014; 4: 7109. https://doi.org/10.1038/srep07109.

16. Wu SY, Li HY, Lin SW. Effects of the workplace violence on the sub-health status of nurses. Chin J Ind Hyg Occup Dis 2011; 29(12): 932-936.

17. Johnson SL. International perspectives on workplace bullying among nurses: a review. Int Nurs Rev. 2009; 56(1): 34-40.

18. Song C, Wang G, Wu H. Frequency and barriers of reporting workplace violence in nurses: An online survey in China. Int J Nurs Sci. 2020; 8(1): 65-70.

19. Qi YK, Xiang YT, An FR, Wang J, Zeng JY, Ungvari GS, et al. Nurses' work-related stress in China: a comparison between psychiatric and general hospitals. Perspect Psychiatr Care 2014; 50(1): 27-32.

20. Hassankhani H, Parizad N, Gacki-Smith J, Rahmani A, Mohammadi E. The consequences of violence against nurses working in the emergency department: a qualitative study. Int Emerg Nurs 2018; 39: 20-25.

21. Choi SH, Lee H. Workplace violence against nurses in Korea and its impact on professional quality of life and turnover intention. J Nurs Manag. 2017; 25(7): 508-518. https://doi.org/10.1111/jonm.12488 